\title{
Isolation of 2 Bacillus Strains with Strong Fibrinolytic Activities from Kimchi
}

\author{
Zhuang Yao ${ }^{1}$, Yu Meng ${ }^{1}$, Huong Giang Le', Se Jin Lee', Hye Sung Jeon ${ }^{1}$, Ji Yeon Yoo ${ }^{1}$, Diana Nur Afifah ${ }^{3}$, and \\ Jeong Hwan Kim ${ }^{1,2 *}$ \\ ${ }^{1}$ Division of Applied Life Science (BK21 Four), Graduate School, ${ }^{2}$ Institute of Agriculture and Life Science, Gyeongsang National University, \\ Jinju 52828, Republic of Korea \\ ${ }^{3}$ Nutrition Science Department, Faculty of Medicine, Diponegoro University, Semarang 50275, Indonesia
}

Received: March 17, 2020 / Revised: May 5, 2020 / Accepted: May 7, 2020

Two Bacillus strains, K3 and K208, both demonstrating strong fibrinolytic activities were isolated from Kimchi, a traditional Korean preparation of fermented vegetables. Isolates were subjected to various molecular biology based identification methods including RAPD-PCR and identified as B. subtilis and B. velezensis, respectively. Tryptic soy broth (TSB) was found to best maintain both the growth and the fibrinolytic activity of these strains. Culture supernatants were analyzed by SDS-PAGE and fibrin zymography, and the results indicate that a 40 and $27 \mathrm{kDa}$ band seem to be responsible for the fibrinolytic activities of these two isolates and the $27 \mathrm{kDa}$ band was subsequently identified as the mature form of AprE, the major fibrinolytic enzyme. Thus the aprE genes were cloned and the translated amino acid sequences demonstrated $99.3 \%$ identity with each other, and $86.5 \%$ identity with BsfA, a fibrinolytic enzyme from B. subtilis ZA400 also isolated from Kimchi, and AprE2, a fibrinolytic enzyme from B. subtilis CH3-5 isolated from Cheonggukjang, a traditional Korean fermented soy. Given this B. subtilis K3 and B. velezensis K208 may be promising starter cultures in the production of fermented foods.

Keywords: Bacillus subtilis, Bacillus velezensis, fibrinolytic enzymes, aprE gene cloning

\section{Introduction}

Bacilli are widely present among diverse environments including soil, water, fermented foods, and intestines of animals [1, 2]. Bacilli secrete various hydrolytic enzymes into surrounding environments, and amylases and proteases are the most important enzymes widely utilized for various industrial applications [3]. Many commercial products including fermented foods depend on the strong enzyme activities of bacilli. Bacilli play important roles during fermentation of soy products such as doenjang (fermented soy paste), ganjang (soy sauce), and cheonggukjang (fermented and boiled soy)

\section{*Corresponding author}

Tel: +82-55-772-1904, Fax: +82-55-772-1909

E-mail: jeonghkm@gnu.ac.kr

๑) 2020, The Korean Society for Microbiology and Biotechnology due to their high proteolytic activities [4-6]. During fermentation, bacilli contribute to the development of unique flavor and texture of foods by producing peptides and amino acids from proteins, functional materials such as $\gamma$-PGA (polyglutamic acid) [7]. Bacilli also produce a variety of different antimicrobial compounds including antibiotics, bacteriocins, and lipopeptides, which inhibit growth of pathogens [8]. Some secreted proteases show strong fibrinolytic activities, and nattokinase and Bacillopeptidase-F (Bpr) are the enzymes with strong fibrinolytic activities and currently used as nutritional supplements or alternatives replacing drugs for treating or preventing thrombolysis caused by fibrin accumulation in blood vessels [9, 10].

Bacillus species with strong fibrinolytic activities, especially classified as GRAS (generally recognized as safe), have potentials to be used as starters for the pro- 
duction of fermented foods. Since such Bacillus species are widely present among fermented foods, it is necessary to isolate novel strains with strong fibrinolytic activities, and test their potentials as starters for fermented foods. Unlike fermented soy foods, Bacillus species have been rarely isolated from Kimchi. Here, we report isolation of 2 Bacillus strains from kimchi and their fibrinolytic activities.

\section{Materials and Methods}

\section{Isolation and identification of bacilli with strong fibrino- lytic activities}

Fermented foods including various Jeotgal and Kimchi products were purchased at Jungang market in Jinju in July, 2019, and used as sources for the isolation of bacilli with fibrinolytic activities. Samples were homogenized by using Stomacher 80 (Seward, UK), and then serially diluted with sterile water. Diluted samples were spreaded onto Luria-Bertani (LB, tryptone $10 \mathrm{~g}$, yeast extract $5 \mathrm{~g}, \mathrm{NaCl} 5 \mathrm{~g}$ per liter, $\mathrm{pH} 7.0$ ) agar plates with skim milk (MB cells, Korea, 2\%, w/v). Plates were incubated for 2 days at $37^{\circ} \mathrm{C}$. Colonies showing halos were selected, and examined for fibrinolytic activities by fibrin plate method as described previously [11].

Colonies showing strong fibrinolytic activities on fibrin plates were selected and identified by molecular biological methods. 16S rRNA genes were amplified using primers: bac-F (5'-CGGCGTGCCTAATACATGCAAG-3'), and bac-R (5'-GGCATGCTG ATCCGCATTACTA-3') [12]. Primers for $r e c A$ was amplified using primers: recA-F (5'-TGAGTGATCGTCAGGCAGCCTTAG-3'), and recAR (5'-CYTBRGATAAGAR TACCAWGMACCGC-3') [12]. PCR was done in $50 \mu \mathrm{l}$ volume consisting of $2 \mu \mathrm{l}$ of template DNA, $2 \mu \mathrm{l}$ of primers $(10 \mu \mathrm{M}$ each), $5 \mu \mathrm{l}$ of dNTPs $(0.25 \mathrm{mM})$, and $0.5 \mu \mathrm{l}$ of Ex Taq DNA polymerase (Takara, Japan). PCR conditions were as follows: initial denaturation at $94^{\circ} \mathrm{C}, 5 \mathrm{~min}$ followed by 30 cycles consisting of denaturation at $94^{\circ} \mathrm{C}, 30 \mathrm{~s}$, annealing at $58^{\circ} \mathrm{C}, 30 \mathrm{~s}$, and extension at $72^{\circ} \mathrm{C}, 1 \mathrm{~min}$, and final extension at $72^{\circ} \mathrm{C}, 4 \mathrm{~min}$.

RAPD-PCR was done using S30 (5'-GTGATCGCAG3') primer and Go-Taq ${ }^{\circledR}$ DNA polymerase (Promega, USA) [12]. PCR was done in $30 \mu \mathrm{l}$ volume consisting of $2 \mu \mathrm{l}$ of template DNA, $2 \mu \mathrm{l}$ of $\mathrm{S} 30$ primer $(10 \mu \mathrm{M})$, and $15 \mu \mathrm{l}$ of Go $\mathrm{Taq}^{\circledR}$ green master mix. PCR conditions were as follows: initial denaturation at $94^{\circ} \mathrm{C}, 5 \mathrm{~min}$ followed by 40 cycles consisting of denaturation at $94^{\circ} \mathrm{C}, 15 \mathrm{~s}$, annealing at $32^{\circ} \mathrm{C}, 15 \mathrm{~s}$, and extension at $72^{\circ} \mathrm{C}, 2 \mathrm{~min}$, and final extension at $72^{\circ} \mathrm{C}, 4 \mathrm{~min}$.

\section{Growth and fibrinolytic activities of bacilli isolates}

Bacilli isolates were grown in different culture media: LB broth, brain heart infusion (BHI, Becton, Dickinson, and Company, USA) broth, nutrient broth (NB, Neogen, USA), and tryptic soy broth (TSB, Becton, Dickinson, and Company) at $37^{\circ} \mathrm{C}$ with shaking. Aliquots of culture were taken at $12 \mathrm{~h}$ intervals, and $\mathrm{OD}_{600}$ values were measured. Culture was centrifuged at $12,000 \times g, 4^{\circ} \mathrm{C}$ for $5 \mathrm{~min}$, and the supernatant was obtained and used as a sample for fibrinolytic activity measurement. Fibrinolytic activity (FA) was measured by fibrin plate method as described previously [11]. The size of the clear zone that formed was converted into plasmin units (U) by comparing it to zones formed by known quantities of plasmin (USA). A standard curve showing the relationship between the clear zone formed and the number of plasmin units was prepared in the range of 2-40 mU.

\section{SDS-PAGE and fibrin zymography}

B. subtilis $\mathrm{K} 3$ and B. velezensis $\mathrm{K} 208$ were grown in TSB at $37^{\circ} \mathrm{C}$ for $96 \mathrm{~h}$. Aliquots were taken at $12 \mathrm{~h}$ intervals. Culture supernatant was prepared and analyzed by SDS-PAGE and fibrin zymography. 10\% acrylamide gels with $5 \%$ stacking gels were used for SDS-PAGE and fibrin zymography. For SDS-PAGE, culture supernatant was first concentrated by trichloroacetic acid (TCA) precipitation method and then $10 \mu \mathrm{g}$ was loaded into each well. For fibrin zymography, $1 \mu \mathrm{g}$ of sample was loaded without TCA concentration. SDS-PAGE and fibrin zymography were done according to a method previously reported [11].

\section{Cloning of aprE genes}

aprE genes were cloned by PCR. Primers used were as follows: CH51-F (5'-AGGATCCCAAGAGAGCGATTGCGGCTGTGTAC-3', BamHI site underlined) and CH51-R (5'-AGAATTCTTCAGAGGGAGCCACCCGTCGATCA-3', EcoRI site underlined) [13]. PCR was done in $50 \mu \mathrm{l}$ volume consisting of $1 \mu \mathrm{l}$ of template DNA, $2 \mu \mathrm{l}$ of each primers (10 $\mu \mathrm{M}$ each), $5 \mu \mathrm{l}$ of dNTPs 
(0.25 mM), and $0.5 \mu \mathrm{l}$ of Ex Taq DNA polymerase. PCR conditions were initial denaturation at $94^{\circ} \mathrm{C}$, 5 min followed by 30 cycles consisting of denaturation at $94^{\circ} \mathrm{C}, 30 \mathrm{~s}$, annealing at $60^{\circ} \mathrm{C}, 30 \mathrm{~s}$, and extension at $72^{\circ} \mathrm{C}, 1 \mathrm{~min}$, and final extension at $72^{\circ} \mathrm{C}, 4 \mathrm{~min}$. Amplified fragments $(1.5 \mathrm{~kb})$ were ligated with pGEM-T-Easy (Promega). Ligation mixture was used to transform $E$. coli DH5 $\alpha$ competent cells by electroporation, and $E$. coli cells harboring recombinant plasmid were screened on LB agar plates with ampicillin $(50 \mu \mathrm{g} / \mathrm{ml})$, 5-bromo4-chloro-3-indolyl- $\beta$-D-galactoside (X-gal, $80 \mu \mathrm{g} / \mathrm{ml}$ ), and isopropyl $\beta$-D-1-thiogalactopyranoside (IPTG, $0.5 \mathrm{mM}$ ). Plasmid from a white colony was extracted and sent for sequencing. Nucleotide sequences were analyzed by BLAST at national center for biotechnology (NCBI).

\section{Results and Discussion}

\section{Isolation and identification of bacilli with strong fibrino- lytic activities}

Bacilli were isolated from various Jeotgal and Kimchi products, and many of them showed proteolytic activities on LB agar plates with skim milk (data not shown). Strains with strong proteolytic activities were further tested for the fibrinolytic activities by fibrin plate method. Two isolates, K3 and K208, showed strong fibrinolytic activities, and both strains were isolated from Kimchi. Blast analyses of $16 \mathrm{~S}$ rRNA and recA genes of K3 indicated that K3 was either B. subtilis, B. amyloliquefaciens, B. siamensis, or B. velezensis (Table 1). Similarly, K208 was either B. amyloliquefaciens, $B$. methylotrophicus, B. pumilus, B. siamensis, B. subtilis, or $B$. velezensis. Considering that the $16 \mathrm{~S}$ rRNA sequences among Bacillus species are highly identical (>99\%), recA gene sequences were used for accurate identification of isolates. Due to the fundamental role of RecA, recA gene is ubiquitous, and has been used as a phylogenetic marker for distantly related species [14]. The results showed that both $16 \mathrm{~S}$ rRNA and recA gene sequences are highly conserved among these closely related Bacillus species, and the sequencing data alone was not enough for the accurate identification of bacilli isolates at species level [15]. RAPD-PCR was done to determine the species of K3 and K208. The RAPD-PCR profiles clearly showed that K3 was B. subtilis, and K208 B. velezensis, and the merit of RAPD-PCR for distinguishing closely related Bacillus species (Fig. 1). Accordingly, K3 was named as B. subtilis K3, and K208 as B. velezensis K208. Other isolates, K52 and M7, showed the same profiles with that of K208, thus they were probably B. velezensis, too. The Genbank accession numbers for $16 \mathrm{~S}$ rRNA gene and $\operatorname{rec} A$ gene were

Table 1. Identification of K3 and K208 by 16S rRNA and recA genes sequencing.

\begin{tabular}{|c|c|c|c|c|}
\hline Strain & Gene & Length (bp) & Description & Identities (\%) \\
\hline \multirow[t]{8}{*}{ K3 } & 16S rRNA & 1,234 & Bacillus subtilis & 100.00 \\
\hline & & & Bacillus amyloliquefaciens & \\
\hline & & & Bacillus siamensis & \\
\hline & & & Bacillus velezensis & \\
\hline & recA & 763 & Bacillus velezensis & 99.87 \\
\hline & & & Bacillus amyloliquefaciens & 99.74 \\
\hline & & & Bacillus subtilis & 99.48 \\
\hline & & & Bacillus vallismortis & 99.21 \\
\hline \multirow[t]{10}{*}{ K208 } & $16 \mathrm{~S}$ rRNA & 1,198 & Bacillus amyloliquefaciens & 100.00 \\
\hline & & & Bacillus velezensis & \\
\hline & & & Bacillus subtilis & \\
\hline & & & Bacillus siamensis & \\
\hline & & & Bacillus methylotrophicus & \\
\hline & & & Bacillus pumilus & \\
\hline & recA & 705 & Bacillus velezensis & 100.00 \\
\hline & & & Bacillus amyloliquefaciens & 99.72 \\
\hline & & & Bacillus subtilis & 99.29 \\
\hline & & & Bacillus vallismortis & 99.15 \\
\hline
\end{tabular}




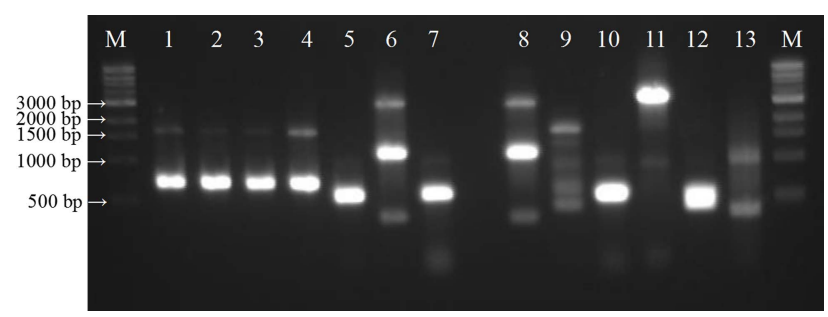

Fig. 1. RAPD-PCR profiles of some isolates and reference strains. $M$, size marker (iVDye $1 \mathrm{~kb}$ DNA ladder, GenDEPOT, USA); 1, K52; 2, K208; 3, M7; 4, B. velezensis ATCC17177; 5, B. subtilis ATCC33234; 6, B. circulans ATCC4513; 7, K3; 8, B. amyloliquefaciens ATCC23845, 9, B. thuringiensis ATCC33679; 10, B. subtilis ATCC6051A; 11, B. mycoides ATCC6465; 12, B. tequilensis ATCC15944; 13, K117.

MT093345 and MN974487 for B. subtilis K3, and MT093346 and MN974488 for B. velezensis K208.

Growth and fibrinolytic activities of B. subtilis K3 and B. velezensis $\mathrm{K} 208$

B. subtilis K3 grew well on LB, BHI, and TSB, reach- ing the OD600 values of 1.73 to 1.74 in $60 \mathrm{~h}$, but grew poor on NB, reaching the OD600 value of 1.28 at $24 \mathrm{~h}$ (Fig. 2A). TSB was the best medium for the fibrinolytic activity and the highest fibrinolytic activity $(70.01 \mathrm{mU} /$ $\mu \mathrm{l})$ was observed at $24 \mathrm{~h}$. The activity decreased slowly until $48 \mathrm{~h}(62.77 \mathrm{mU} / \mu \mathrm{l})$ (Fig. 2B), and then the activity decreased rapidly after $48 \mathrm{~h}$, showing only $0.56 \mathrm{mU} / \mu \mathrm{l}$ at $60 \mathrm{~h}$. LB was the second best medium for fibrinolytic activity, and the highest activity $(40.40 \mathrm{mU} / \mu \mathrm{l})$ was shown at $24 \mathrm{~h}$, and then the activity decreased rapidly. Cultures on all 4 media showed basal levels of activities at $60 \mathrm{~h}$ and thereafter. The pattern is somewhat different from those of other fibrinolytic bacilli where fibrinolytic activities are increased at the beginning of stationary phase or late log phase, and the activity is maintained during stationary phase, often showing the highest activity around 84-96 h of incubation [16, 17]. The results indicated that the fibrinolytic activity profile is different among bacilli, and thus each isolate should be examined individually.
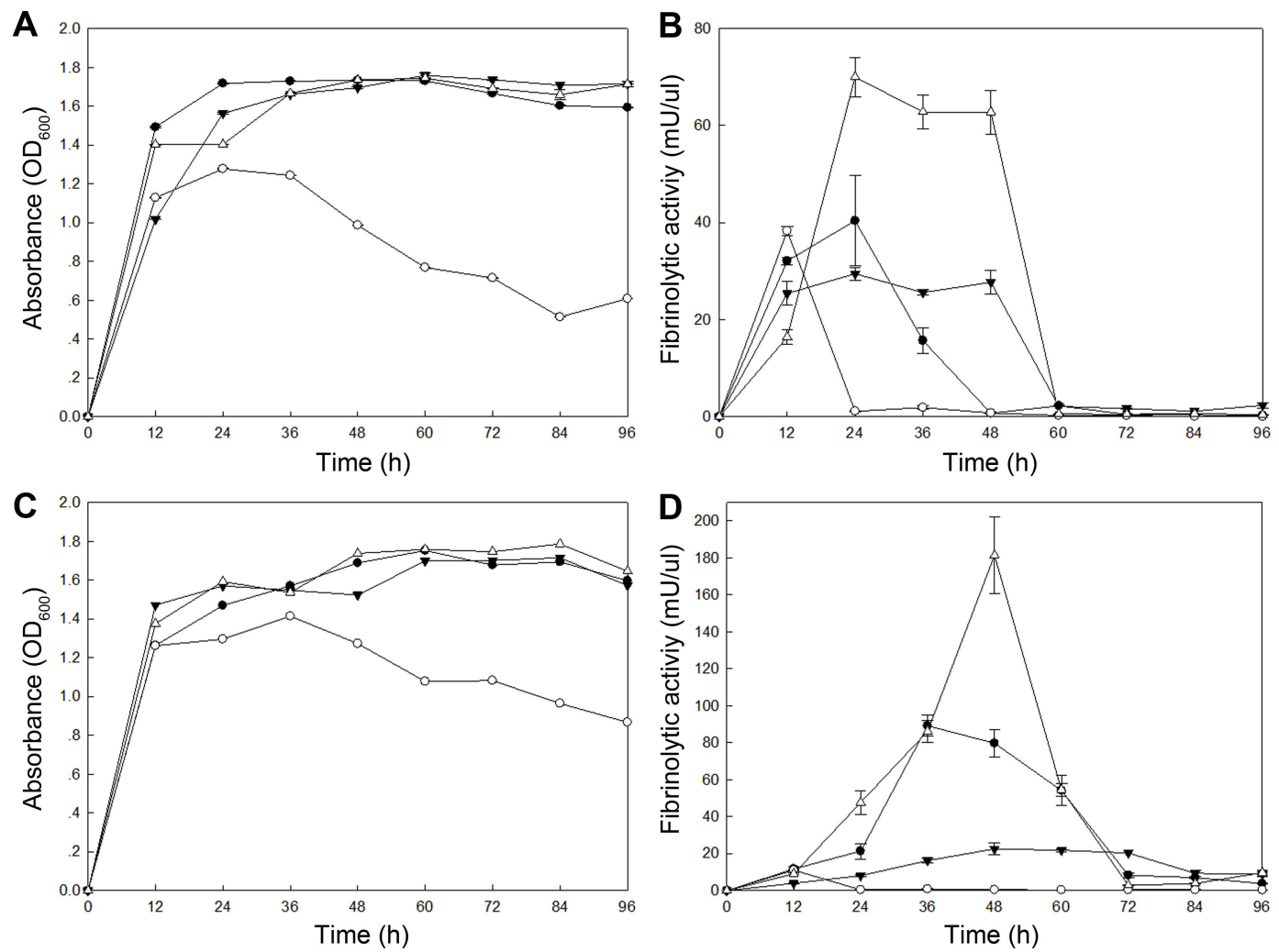

Fig. 2. Growth and fibrinolytic activities of Bacillus isolates in different culture media. B. subtilis $\mathrm{K} 3$ and $B$. velezensis $\mathrm{K} 208$ were grown at $37^{\circ} \mathrm{C}$ for $96 \mathrm{~h}$ in 4 different media. $\mathrm{OD}_{600}$ values and fibrinolytic activities were measured at $12 \mathrm{~h}$ intervals. Growth of $B$. subtilis K3 (A) and B. velezensis K208 (C). Fibrinolytic activity of B. subtilis K3 (B) and B. velezensis K208 (D). -•- LB; - o- NB; - $\Delta-\mathrm{TSB} ;-\mathbf{\nabla}-\mathrm{BHI}$. 
B. velezensis K208 showed growth curves on 4 media which were quite similar with those of B. subtilis K103. But the fibrinolytic profiles of $B$. velezensisK208 were different from those of $B$. subtilis K3. Although TSB was the best medium for the fibrinolytic activity, the highest activity (181.49 mU/ $\mu \mathrm{l})$ was observed at $48 \mathrm{~h}$ (Fig. 2D). The activity decreased rapidly thereafter, and remained at basal level at $72 \mathrm{~h}(2.85 \mathrm{mU} / \mu \mathrm{l})$ and thereafter. Unlike B. subtilis $\mathrm{K} 3$ culture, higher activities were maintained for short period, just around $48 \mathrm{~h}$. LB was the second best medium for the fibrinolytic activity, and the highest activity on $\mathrm{LB}$ was observed at $36 \mathrm{~h}(89.18 \mathrm{mU} / \mu \mathrm{l})$. NB was the poorest medium for the growth and fibrinolytic activity of $B$. velezensis K208 (Fig. 2C, 2D).

\section{SDS-PAGE and fibrin zymography}

SDS-PAGE of culture supernatant of B. subtilis K3 showed that the band intensity of a $27 \mathrm{kDa}$ protein, corresponding to the mature AprEK3, was higher at 12, 24, 36 , and $48 \mathrm{~h}$ than that of other time points. The results matched well with the fibrinolytic activity measurements of culture grown on TSB (Fig. 2). The intensity of ca $40 \mathrm{kDa}$ band was also higher at $12-36 \mathrm{~h}$ time points on the SDS-gel, and especially the highest at 24 and 36 h. Since, B. subtilis K3 showed higher fibrinolytic activity in TSB at this time points, the $40 \mathrm{kDa}$ protein might contribute to the higher fibrinolytic activity of $B$. subtilis K3. Characterization of the $40 \mathrm{kDa}$ protein will confirm its identity and any role on the fibrinolytic activity of B. subtilis K3 in TSB. However, a $27 \mathrm{kDa}$ band was observed on a fibrin zymogram at $60 \mathrm{~h}$. The reason for the discrepancy between fibrinolytic activity measurements (Fig. 2B) and fibrin zymogram (Fig. 3B) is not clear.

SDS-PAGE of culture supernatant from B. velezensis K208 showed similar pattern with that from B. subtilis K3. Intensity of a $40 \mathrm{kDa}$ protein was higher at 24-48 h, and the same is true for $27 \mathrm{kDa}$ band. Culture showed higher fibrinolytic activities at this time period, too (Fig. 2D). On a fibrin zymogram, the $27 \mathrm{kDa}$ band appeared at $48 \mathrm{~h}$ and thereafter, and the band intensity was the highest at $72 \mathrm{~h}$. A $35 \mathrm{kDa}$ band was also observed at stationary phase on a fibrin zymogram. The mature form of AprE, $27 \mathrm{kDa}$ insize, appears at the stationary growth phase for some Bacillus species such as $B$. amyloliquefaciens CH86-1 isolated from Cheongguk-

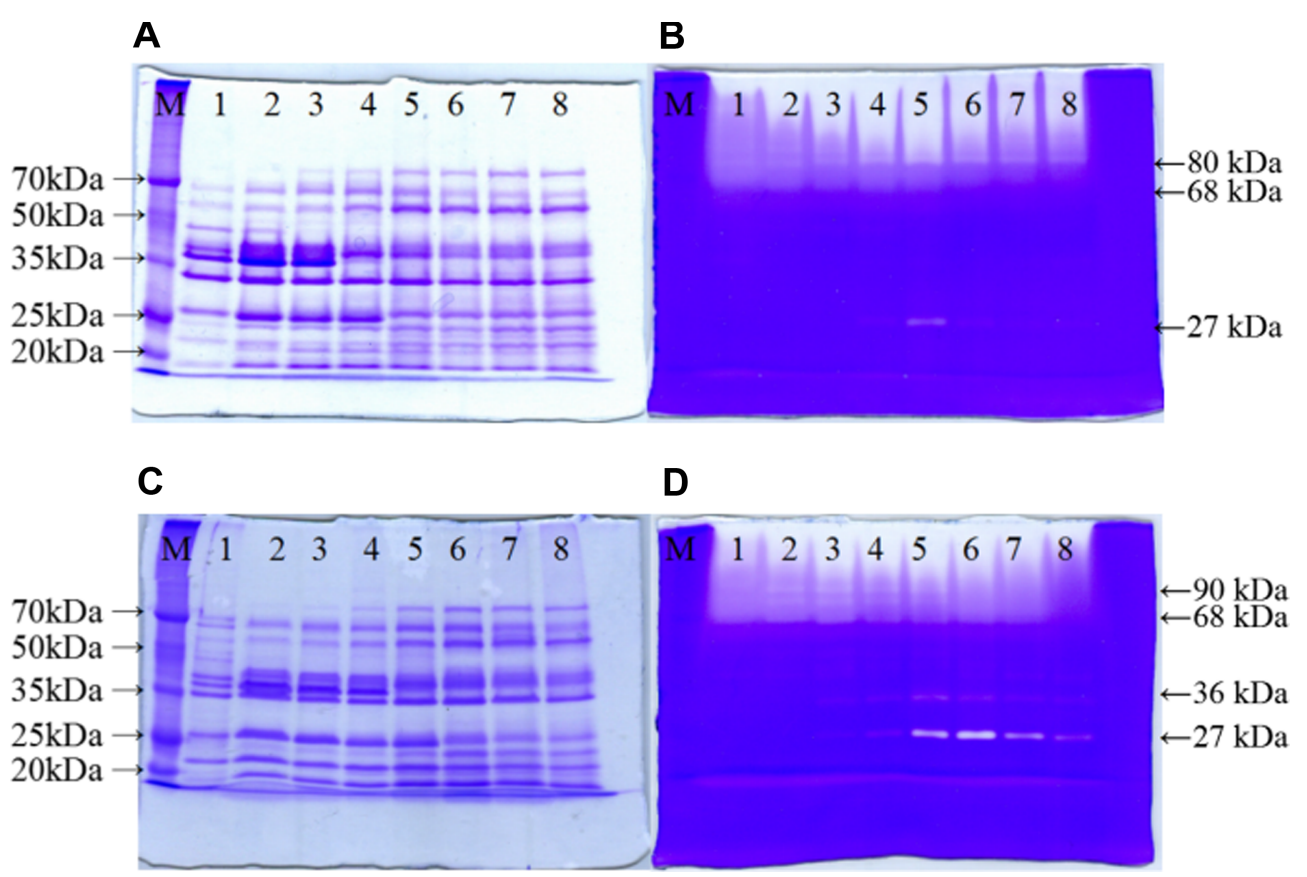

Fig. 3. SDS-PAGE and fibrin zymogram of culture supernatant. B. subtilis $\mathrm{K} 3$ and $B$. velezensis $\mathrm{K} 208$ were grown in TSB at $37^{\circ} \mathrm{C}$ with aeration. Culture supernatant was taken out at $12 \mathrm{~h}$ intervals. SDS-PAGE (A, B. subtilis K3; C, B. velezensis K208) and fibrin zymography (B, B. subtilis K3; D, B. velezensis K208) were done. M: Dokdo-marker EBM-1034 (Elpis Biotech, Korea); 1, 12 h; 2, 24 h; 3, 36 h; 4, 48 h; 5, 60 h; 6, 72 h; 7, 84 h; 8, 96 h. 


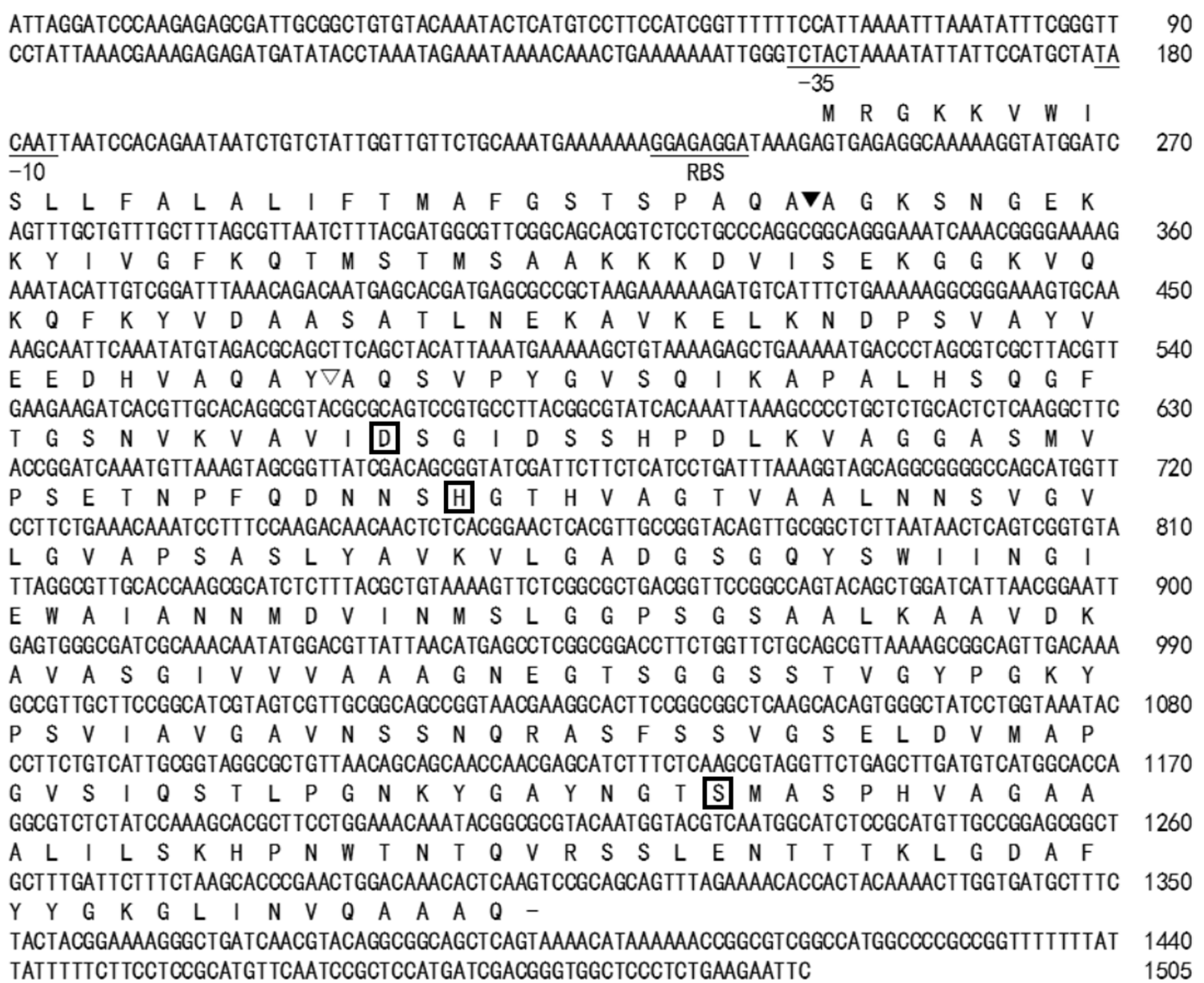

Fig. 4. Nucleotide sequence and translated amino acid sequence of aprEK3. Possible -35 and -10 promoter sequences are underlined together with ribosome binding site (RBS). Signal peptide cleavage site $(\boldsymbol{\nabla})$ and proenzyme cleavage site $(\nabla)$ are marked. Amino acids consisting of the catalytic triad $\left(\mathrm{Asp}^{32}, \mathrm{His}^{64}\right.$, and $\left.\mathrm{Ser}^{221}\right)$ are marked with boxes.

jang [18] as shown by fibrin zymography for the culture supernatant. But the same band appeared at earlier time points for other Bacillus species such as B. subtilis JS2 isolated from saeu Jeotgal [19], indicating the possible operation of different regulatory systems for aprE gene expression among Bacillus species.

\section{Cloning of aprE genes}

aprEK3 and aprEK208 were cloned after PCR amplification and sequenced. BLAST analyses of both genes confirmed that the 2 genes show very high identities with homologous aprE genes from Bacillus species (results not shown). Genbank number is MT093822 for aprEK3, and MT093821 for aprEK208. Both aprEK3 and aprEK208 genes encode preproenzyme consisting of 382 amino acids (Fig. 4, only aprEK3 shown). The first 30 amino acids correspond to signal peptide as judged from Signal P4.1 Server (Technical University of
Denmark) and the next 77 amino acids corresponded to a prosequence as judged from comparisons with other fibrinolytic enzymes (results not shown). The mature enzyme consists of 275 amino acids. The calculated size and $\mathrm{pI}$ of mature AprEK3 were 27,460.60 and 6.65, and 27,490.62 and 6.65 for AprEK208.

When translated amino acid sequences were compared with each other, 2 amino acids were different (99.3\% identity). The $91^{\text {th }}$ and $268^{\text {th }}$ amino acid of AprEK3 were $\mathrm{N}$ and $\mathrm{G}$ whereas they were $\mathrm{K}$ and $\mathrm{S}$ for AprEK208. Amino acids constituting of the catalytic triad are conserved in AprEK3 and AprEK208, and they are Asp $\left(32^{\text {th }}\right)$, His $\left(64^{\text {th }}\right)$. and Ser $\left(221^{\text {th }}\right)$ (Fig. 4). When the mature AprEK3 was compared with BsfA, a fibrinolytic enzyme from B. subtilis ZA400 isolated from Kimchi, $86.5 \%$ identity (238/275) was observed [20]. Total 37 amino acids were different, and 18 amino acids were located in prepro part. AprEK3 also showed 86.5\% 
identity (238/275) with AprE2, a fibrinolytic enzyme from B. subtilis CH3-5 isolated from Cheonggukjang [21]. PreproAprEK3 consists of 382 amino acids, but prepro BsfA and AprE2 consist of 381 amino acids, one amino acid shorter than AprEK3. The signal peptide of prepro AprEK3 consists of 30 amino acids, but that of prepro BsfA is 26 amino acids, and prepro AprE2 is 29 amino acids. Depending upon each strain, B. subtilis strains produce similar fibrinolytic enzymes, but still significant differences are observed among them. Therefore further studies are necessary to find out different enzymes in the primary structure have different roles during growth. The highly identical amino acid sequences indicates the highly conserved nature of AprEs among Bacillus species, implying the important roles of AprE for Bacillus species during stationary growth phase. Proteases such as AprE not only provide peptides and amino acids but also play other important roles. Some proteases are responsible for the conversion of pheromeones such as CSF (competence and sporulation factor), responsible for quorum sensing [22]. AprE is also reported to be involved in the processing of subtilin, a peptide antibiotic [23].

Bacilli are often isolated from Kimchi as shown in this work and a previous report [20]. But their roles for Kimchi fermentation and storage have rarely been examined. This is probably due to the general belief that bacilli are inhibited by acids produced by lactic acid bacteria during Kimchi fermentation. But bacilli can remain viable as spores for long period of time and can resume growth later when environmental conditions become favorable for bacilli. Further studies on bacilli during Kimchi fermentation and storage might help to better understand any roles of bacilli for Kimchi quality. Bacilli with strong fibrinolytic activities are desirable since they have potentials as starters for some types of fermented foods. In this work, we isolated 2 useful Bacillus strains with strong fibrinolytic activities, and these isolates are promising starters for Jeotgals and other types of fermented foods.

\section{Acknowledgments}

This work was supported by the Basic Science Research Program through the National Research Foundation of Korea (NRF) funded by the Ministry of Education (2017R1D1A1B03030037), and also sup- ported by a grant 20130290 to Solar Salt Research Center of Mokpo National University from Ministry of Oceans and Fisheries of Korea. Yao Z, Meng Y, Lee SJ, and Yoo JY were supported by BK21 Plus program, MOE, Republic of Korea. Le HG and Jeon HS were supported by full-time graduate scholarship from Gyeongsang National University.

\section{Conflict of Interest}

The authors have no financial conflicts of interest to declare.

\section{References}

1. Elshaqhabee FMF, Rokana N, Gulhane RD, Shama C, Panwar H. 2017. Bacillus as a potential probiotics: status, concerns, and future perspective. Front. Microbiol. 8: 1490.

2. Ilinskaya ON, Ulyanova VV, Yarullina DR, Gataullin IG. 2017. Secretome of intestinal bacilli: a natural guard against pathologies. Front. Microbiol. 8: 1666.

3. Schallmey M, Singh A, Ward OP. 2004. Developments in the use of Bacillus species for industrial production. Can. J. Microbiol. 50: 1-17.

4. Kimura K, Yokoyama S. 2019. Trends in the application of Bacillus in fermented foods. Curr. Opin. Biotechnol. 56: 36-42.

5. 5. Ham S-S, Choi K-K, Cui C-B, Lee B-G, Joo D-S, Lee D-S. 2004. Quality characteristics of soy sauce fermented by Bacillus licheniformis NH20 isolated from traditional meju and Aspergillus oryzae. Food Sci. Biotechnol. 13: 537-543.

6. Jeong D-W, Kim H-R, Jung G, Han S, Kim C-T, Lee J-H. 2014. Bacterial community migration in the ripening of doenjang, a traditional Korean fermented soybean food. J. Microbiol. Biotechnol. 24: 648-660.

7. Kada S, Ishikawa A, Ohshima Y, Yoshida K. 2013. Alkaline serine protease AprE plays an essential role in poly- $\gamma$-glutamate production during natto fermentation. Biosci. Biotechnol. Biochem. 77: 802-809.

8. Stein T. 2005. Bacillus subtilis antibiotics: structures, syntheses and specific functions. Mol. Microbiol. 56: 845-857.

9. Chen H, McGowan EM, Ren N, Lal S, Nassif N, Shad-Kaneez F, et al. 2018. Nattokinase: a promising $g$ alternatoive in prevention and treatment of cardiovascular diseases. Biomark. Insights 13: 1177271918785130.

10. Omura K, Hitosugi $M$, Zhu X, Ikeda $M$, Maeda $H$, Tokudome S. 2005. A newly derived protein from Bacillus subtilis natto with both antithrombotic and fibrinolytic effects. J. Pharmacol. Sci. 99: 247-251.

11. Yao Z, Kim JA, Kim JH. 2019. Characterization of a fibrinolytic enzyme secreted by Bacillus velezensis BS2 isolated from sea squirt jeotgal. J. Microbiol. Biotechnol. 29: 347-356.

12. Kwon GH, Lee HA, Park JY, Kim JS, Lim J, Park CS, et al. 2009. Development of a RAPD-PCR method for identification of Bacillus species isolated from cheonggukjang. Int. J. Food 
Microbiol. 129: 282-287.

13. Kim GM, Lee AR, Lee KW, Park JY, Chun J, Cha J, et al. 2009. Characterization of a $27 \mathrm{kDa}$ fibrinolytic enzyme from Bacillus amyloliquefaciens $\mathrm{CH} 51$ isolated from cheonggukjang. J. Microbiol. Biotechnol. 19: 997-1004.

14. Eisen JA. 1995. The RecA protein as a model molecule for the molecular systematic studies of bacteria: comparison of trees of RecAs and 16S RNA from the same species. J. Mol. Evol. 41: 11051123.

15. Celandroni F, Vecchione A, Cara A, Mazzantini D, Lupetti A, Ghelardi E. 2019. Identification of Bacillus species: implication on the quality of probiotic formulations. PLoS One 14: e0217021.

16. Lee AR, Kim GM, Kwon GH, Lee KW, Park JY, Chun J, et al. 2010. Cloning of aprE86-1 gene encoding a 27-kDa mature fibrinolytic enzyme from Bacillus amyloliquefaciens CH86-1. J. Microbiol. Biotechnol. 20: 370-374.

17. Yao Z, Kim JA, Kim JH. 2018. Gene cloning, expression, and properties of a fibrinolytic enzyme secreted by Bacillus pumilus BS15 isolated from gul (oyster) jeotgal. Biotechnol. Bioprocess Eng. 23: 293-301.

18. Lee AR, Kim GM, Park JY, Jo HD, Cha J, Song YS, et al. 2010. Characterization of a $27 \mathrm{kDa}$ fibrinolytic enzyme from Bacillus amyloliquefaciens $\mathrm{CH} 86-1$ isolated from Cheonggukjang. J. Korean Soc. Appl. Biol. Chem. 53: 56-61.

19. Yao Z, Kim JA, Kim JH. 2018. Properties of a fibrinolytic enzyme secreted by Bacillus subtilis JS2 isolated from saeu (small shrimp) Jeotgal. Food Sci. Biotechnol. 27: 765-772.

20. Ahn MJ, Ku HJ, Lee SH, Lee JH. 2015. Characterizatoin of a novel fibrinolytic enzyme, BsfA, from Bacillus subtilis ZA400 in kimchi reveals its pertinence to thrombosis treatment. J. Microbiol. Biotechnol. 25: 2090-2099.

21. Jeong SJ, Kwon GH, Chun J, Kim JS, Park CS, Kwon DY, et al. 2007. Cloning of fibrinolytic enzyme gene from Bacillus subtilis isolated from cheonggukjang and its expression in protease-deficient Bacillus subtilis strains. J. Microbiol. Biotechnol. 17: 1018-1023.

22. Lanigan-Gerdes S, Dooley AN, Faull KF, Lazazzera BA. 2007. Identification of subtilisin, Epr and Vpr as enzymes that ptoduce CSF, an extracellular signaling peptide of Bacillus subtilis. Mol. Microbiol. 65: 1321-1333.

23. Corvey C, Stein T, Düsterhus S, Karas M, Entian KD. 2003. Activation of subtilin precursors by Bacillus subtilis extracellular serine proteases subtilisn (AprE), WprA, and Vpr. Biochem. Biophys. Res. Commun. 304: 48-54. 